\title{
The importance of the sea ice marginal zone for the surface turbulent heat fluxes in Arctic on the basis of NCEP CFSR reanalysis
}

\author{
J. Selivanova ${ }^{1}$, P. Verezemskaya ${ }^{1}$, N. Tilinina ${ }^{1}$, S. Gulev ${ }^{1,2}$, and S. Dobrolyubov ${ }^{2}$
}

Received 28 July 2020; accepted 15 October 2020; published 28 March 2021.

This paper provides the analysis of the role of the marginal ice zone into the air-sea interaction processes over the Arctic during the period 1979-2010 on the basis of NCEP CFSR reanalysis data. One of the major conclusion of this study is the fact that widely used boundary of the interacting with the ocean atmosphere and thermally isolated atmosphere from the ocean of $15 \%$ for the sea ice concentration is not optimal for studies of the air-sea interaction processes. We demonstrated that significant amount of the surface turbulent heat flux is transferred from the ocean to the atmosphere through the areas with sea ice concentrations higher than $15 \%$, while this sea ice concentration criteria is widely used as a boundary of the ice-covered and ice-free ocean. We also show that the spatial pattern of the response of turbulent heat flux to sea ice variability is observed over the Barents and Bering Seas during a cold season and over the Chukchi and Beaufort Seas during a warm season. KEYWORDS: Surface turbulent heat fluxes; marginal ice zone; sea ice concentration; sea ice thickness; Arctic.

Citation: Selivanova, J., P. Verezemskaya, N. Tilinina, S. Gulev, and S. Dobrolyubov (2021), The importance of the sea ice marginal zone for the surface turbulent heat fluxes in Arctic on the basis of NCEP CFSR reanalysis, Russ. J. Earth. Sci., 21, ES2003, doi:10.2205/2020ES000744.

\section{Introduction}

Decrease of the Arctic sea ice during the past decades [Cavalieri and Parkinson, 2012; Cohen, 2014; Onarheim et al., 2018; Vihma, 2014 is associated with changes in the diabatic signals in high latitude oceans and has potential impact on the airsea interaction processes. The largest ice shrinking is observed in September (45\% since 1979 to 2016)

\footnotetext{
${ }^{1}$ Shirshov Institute of Oceanology RAS, Moscow, Russia

${ }^{2}$ Faculty of Geography, Lomonosov Moscow State University, Moscow, Russia

Copyright 2021 by the Geophysical Center RAS. http://rjes.wdcb.ru/doi/2020ES000744-res.html
}

while during March-May the decrease is weaker (about 9\%, [Onarheim et al., 2018]). Stroeve et al. 2014 found the lengthening of the melt-season from 1979 to 2013 at a rate of 5 days per decade, while the freezing time has shifted forward at a rate of 6-11 days per decade during 1979-2016 [Shalina and Bobylev, 2017]. Strong and Rigor 2013 reported seasonally varying trends in the extent of the marginal ice zone (MIZ, ice concentrations from 15 to 80\%) during 1979-2011. During July-September the marginal ice zone increased in width by $13 \mathrm{~km}$ per decade, while in the cold season (February-April) a narrowing trend of $4 \mathrm{~km}$ per decade was reported.

These changes of the marginal ice zone may have a strong impact on the air-sea interaction processes as newly opened ice free areas provide conditions 
for the increase of the surface turbulent heat fluxes, as the water is no longer thermally isolated from the air by the sea ice. One of the major feedbacks in this case is associated with the potential effect on the atmospheric boundary layer and low level baroclinicity in the atmosphere, regional atmospheric dynamics and water vapour content in the atmosphere [Deser et al., 2010, Francis et al., 2009: Serreze et al., 2009; Screen and Simmonds, 2010; Screen et al., 2013; Stroeve et al., 2011, 2014, Yang et al., 2016.

The link between sea ice decline and surface turbulent heat fluxes (latent + sensible, STHF) itself has been quantitatively analyzed in a number of works based on observational and model studies [Ivanov et al., 2019, Zippel and Thomson, 2016. Andreas et al., 1984, 2010, Birnbaum and Lupkes, 2002, Batrak and Muller, 2018, Pope et al., 2020. Maykut et al., 1978 and during the Marginal Ice Zone Experiment [Fairall and Markson, 1987]. Deser et al. 2010 analyse STHF response to the sea ice decline in CCSM3 and CAM3 model outputs and demonstrates that STHF from the ice-free ocean increases from 30 to $90 \%$ locally in the end of the 21st century. Screen et al. 2013 argued that the delay of the surface flux increase due to the seasonal sea-ice variations may modulate the atmospheric circulation response to the sea ice loss in Arctic. Yang et al. 2016 revealed the positive feedback between the heat flux formation and the sea ice behavior during autumn and winter seasons in the Barents Sea. Taylor et al. 2018 demonstrated regional and seasonal inhomogeneities in STHF trends in response to sea-ice trends in Arctic on the basis of satellite data, arguing that the prolonged melting period may have a cumulative effect on the amount of turbulent heat transferred to the atmosphere and on the ability of incoming shortwave radiation to warm the ocean.

In the present study we analyse the long term trends of the sea ice characteristics with the focus on the STHF through the marginal ice zone (MIZ) in the Arctic on the basis of the NCEP-CFSR reanalysis [Saha et al., 2010. Specifically, we focus on the question which was not adressed in the previous works: reliability of fractional ice cover criterion of $15 \%$ for sea ice concentration for quantifying so-called "interacting with the atmosphere ocean" and the "thermally isolated ocean", including the role of the marginal sea-ice zone in air-sea interaction processes.

\section{Data}

We use here 6-hourly sea ice concentration (SIC), sea ice thickness (SIT), as well as sensible and latent surface heat fluxes from NCEP CFSR reanalysis data [Saha et al., 2010] for the period 19792010 with spatial resolution of $0.5^{\circ}$. SIC and SIT in NCEP CFSR is a result from sea ice model [Griffies et al., 2011 and assimilation of high-resolution satellite products implemented by the Gridpoint Statistical Interpolation (GSI) scheme. Surface turbulent heat fluxes over the ice result from the solution of the coupled model in NCEP CFSR. Sea ice extent (SIE) is defined as the fractional area of the ocean with a fractional ice cover of at least $15 \%$ [Cavalieri et al., 1999, Deser et al., 2010, Francis et al., 2009, Serreze et al., 2007, Vihma, 2014.

\section{Results}

Here we qualitatively and quantitatively evaluate the input of the STHF over the MIZ into the total surface turbulent heat flux over the Arctic. Typically, when calculating turbulent heat flux over the Arctic the threshold of $15 \%$ for the sea ice concentration (SIC) is used to define the boundary of the ocean "covered by the ice' and "ice-free ocean" [Tikhonov et al., 2016. In this respect the $15 \%$ SIC threshold widely applied in many studies may be problematic for estimation of the air-sea interaction, because areas with SIC $>15 \%$ might be also characterized by the intense air-sea exchanges. This is shown in Figure 1 demonstrating 2-dimensional distribution of the intensity of STHF over the grid cells with sea ice in the coordinates "SIT-SIC" for March and September. In September a significant amount of the STHF is transferred from the ocean to the atmosphere through the areas with sea ice concentrations higher $15 \%$, the average STHF through SIC from $15 \%$ to $60 \%$ is $20-28 \mathrm{~W} / \mathrm{m}^{2}$, while through the areas with SIC $<15 \%$ it is only $10 \mathrm{~W} / \mathrm{m}^{2}$ higher, being $30-38$ $\mathrm{W} / \mathrm{m}^{2}$. In March the limiting factor for the air-sea interaction is the sea ice thickness, while the average amount of heat transferred through the areas with SIC $>15 \%$ is significant. Thus, diagrams in Figure 1 imply that 15\% SIC threshold is not necessarily effective and that the intense STHF can be also observed over higher SIC, being also dependent on SIT (at least for the autumn conditions). 

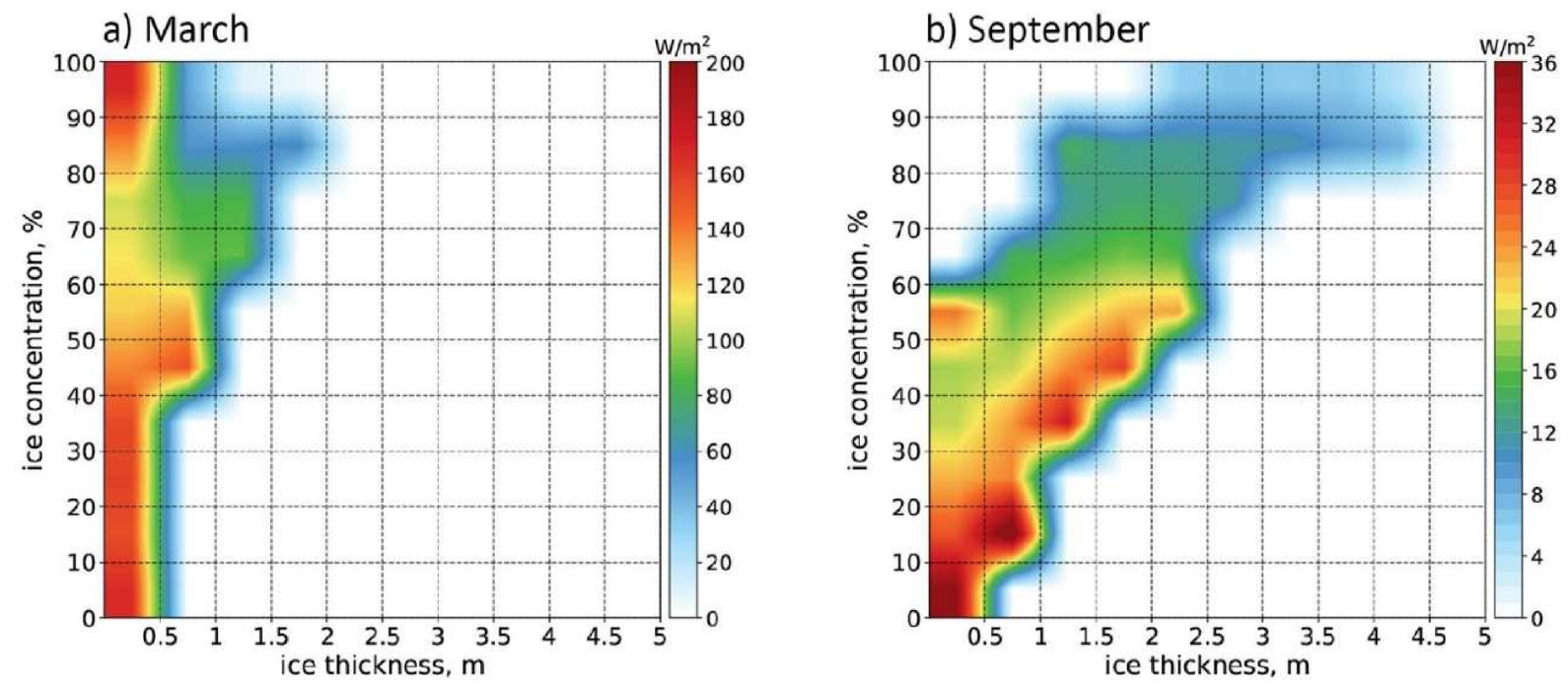

Figure 1. Mean surface turbulent heat flux (latent + sensible) inside the sea ice cover of different thickness (horizontal axis) and concentration (vertical axis) over the Arctic for (a) March and (b) September during 1979-2010 period from NCEP CFSR reanalysis.

Given this, we analysed how SIC and SIT evolved in the Arctic during 1979-2010 period, this analysis provides an assessment of the input of the MIZ into the variations of the STHF over the Arctic.

Figure 2 shows changes in the occurrence anomalies of SIC and SIT for the warm season (August and September) during 1979-2010. The occurrence anomalies were derived from the histograms for individual years with respect to the long-term (19792010) probability distribution. Figure 2a clearly shows a tendency of decreasing SIC over the 32yr period. These means that the areas with SIC from 0 to $50 \%$ are increasing, while areas with SIC $>50 \%$ are decreasing. Given the fact, that these areas characterized by the significant STHFs and also means the widening if the MIZ where atmosphere interacts with the ocean significantly, this signal rather means increase if the air sea interaction over the Arctic. During 1980s and the early 1990s positive anomalies for classes of SIC $>70 \%$ were associated with the negative anomalies for small SIC. This situation has changed in the early 1990s when strongly positive occurrence anomalies are identified for SIC $<40 \%$ and primarily negative anomalies are observed for high SIC (Figure 2a). The area of the multiyear pack ice $(80-100 \%)$ decreased during 1979-2010 period by $1.9 \times 10^{6} \mathrm{~km}^{2}$ (34\%), while the area with SIC $<30 \%$ increased by $0.7 \times 10^{6} \mathrm{~km}^{2}(190 \%)$. Figure $2 \mathrm{~b}$ shows the strong decline in the occurrence of thick ice $(>3 \mathrm{~m})$ (by $1.34 \times 10^{6} \mathrm{~km}^{2}$ since 1982) at the expense of upward tendency in the occurrence of relatively thin ice. These tendencies are also evident in winter (February and March, not shown). Overall SIC has a stronger climatic signal than SIT over the Arctic and demonstrates widening of the MIZ.

It also important to analyze the spatial distribution of the estimates of linear trends of SIC and SIT together with trends of the STHFs (Figure 3). During the cold season (FMA) negative linear trends of SIC (Figure 3a) are most pronounced in the Barents Sea (up to $-20 \%$ per decade). It is important that the response of the STHFs (increasing STHF over the decreasing SIC) is also evident over this area. This finding is consistent with Yang et al. 2016] who reported $-16 \%$ per decade annual loss of in the Barents-Kara Sea region and Onarheim et al. 2018 who indicated $-27 \%$ ice concentration trend in the Barents Sea in March during 1979 2016. The strongest decrease of SIC is identified in the MIZ which is characterized by the most pronounced response of the STHF (trend is $+50 \mathrm{~W} / \mathrm{m}^{2}$ per decade) to the Arctic sea ice loss (Figure 3p). This is consistent with Taylor et al. 2018 who reported trends of $30 \mathrm{~W} / \mathrm{m}^{2}$ per decade for the latent and more than $20 \mathrm{~W} / \mathrm{m}^{2}$ per decade for STHF in winter season from the analysis of satellite data for the period 2003-2015. The opposite tendencies 
a) SIC

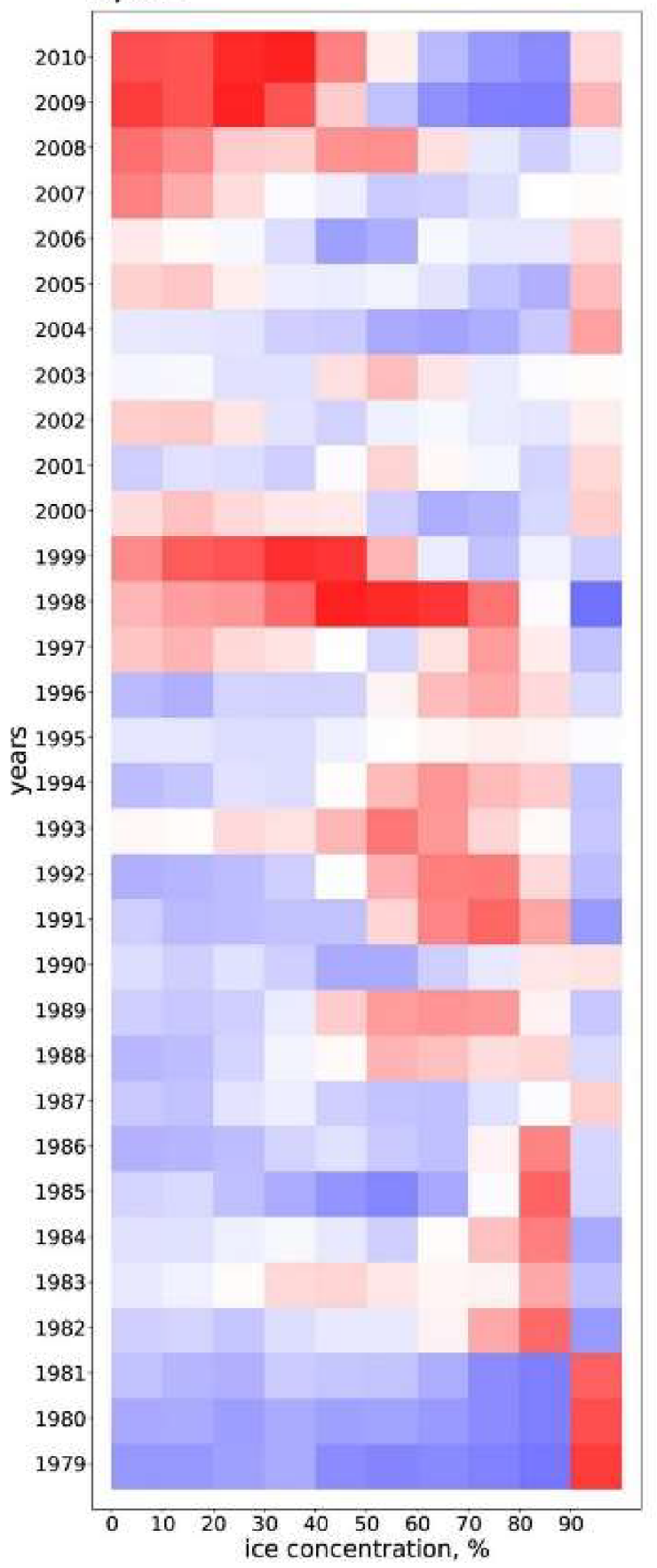

b) SIT

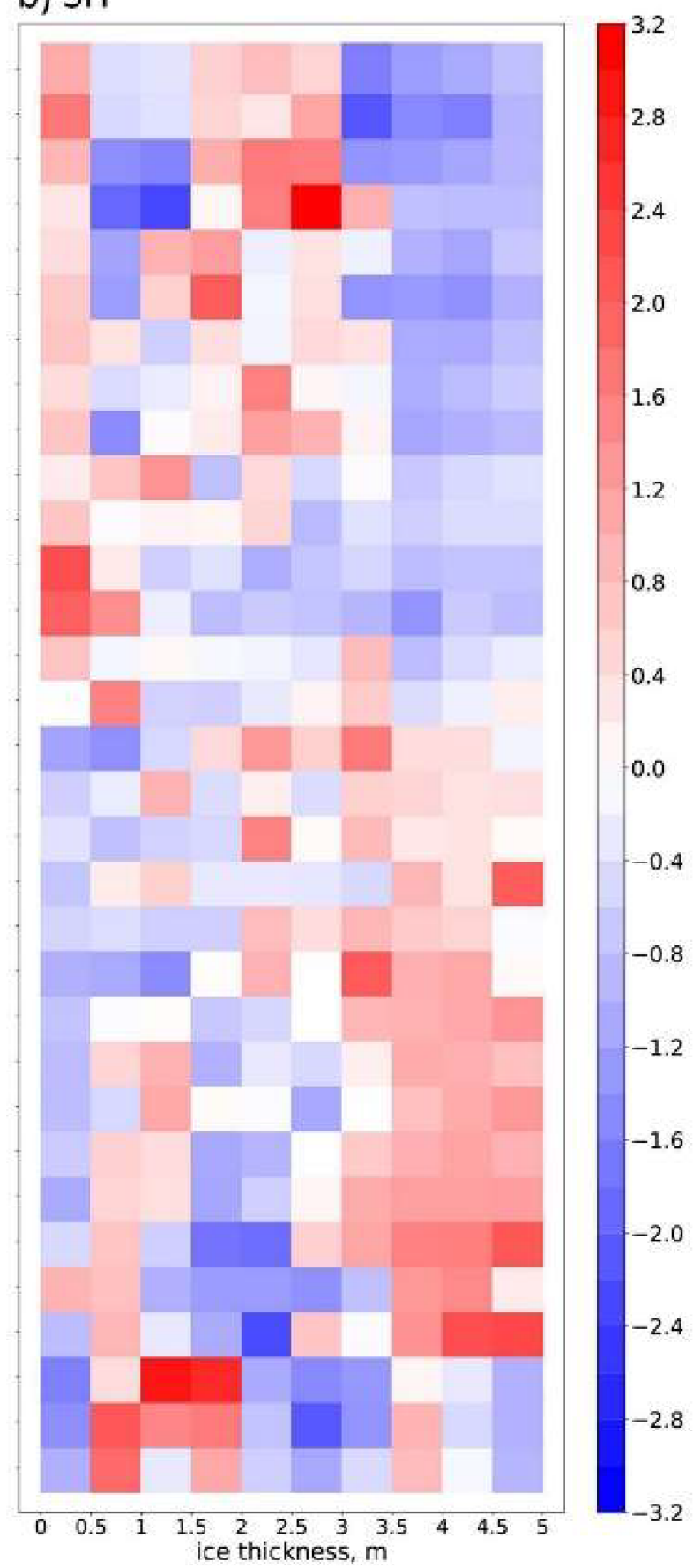

Figure 2. Anomalies of the occurrence of sea-ice of different concentration (a, SIC) and thickness (b, SIT), normalized by the standard deviation in September. Anomalies are calculated over the Arctic, where SIC and SIT are $>0$ for the 1979-2010 period. 


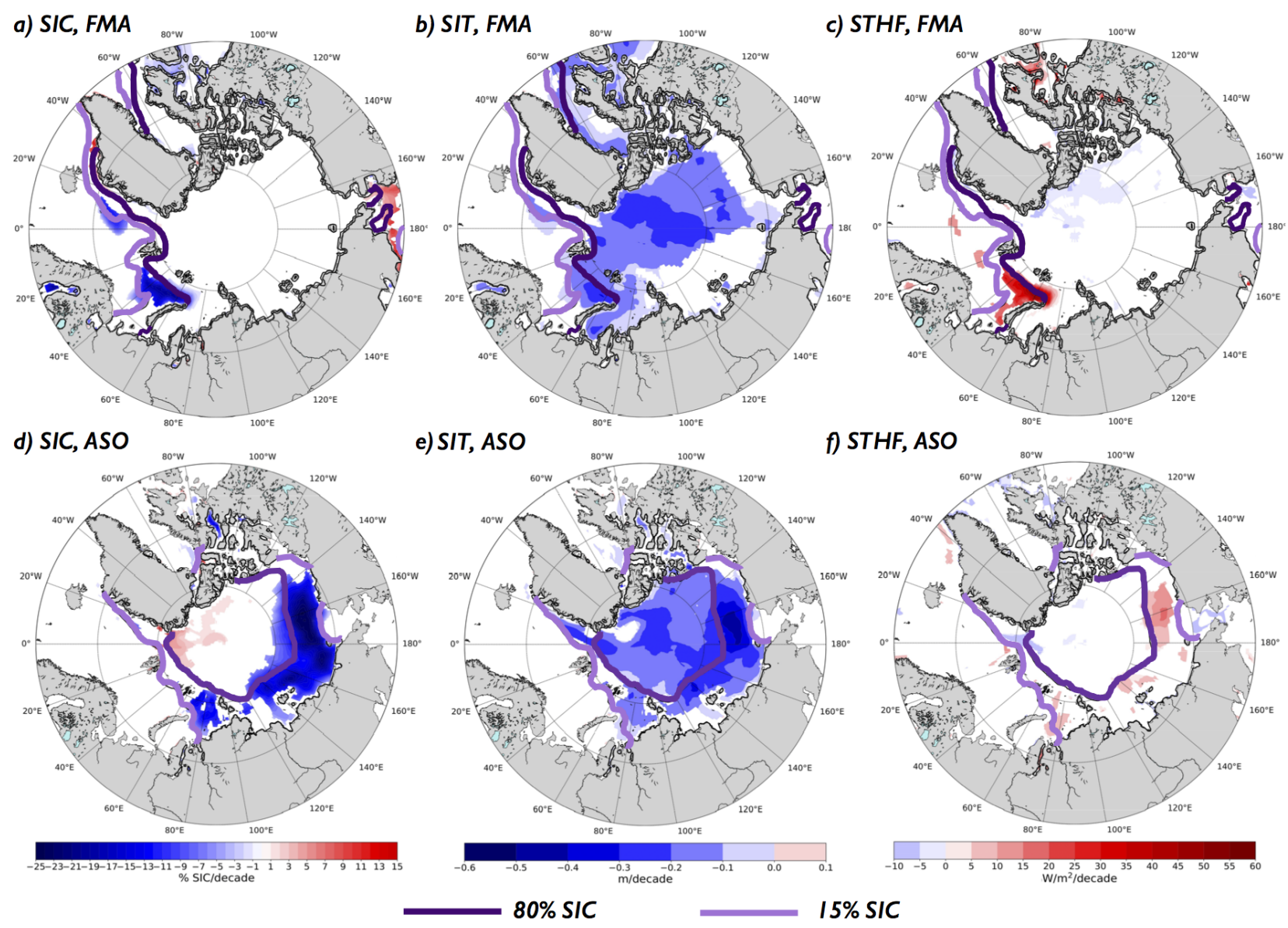

Figure 3. Linear trends of SIC (fraction per decade, a,d), SIT (m per decade, b, e) and STHF $\left(\mathrm{W} / \mathrm{m}^{2}\right.$ per decade, $\left.\mathrm{c}, \mathrm{f}\right)$ for cold (FMA, upper panel) and warm (ASO, lower panel) seasons. Trends are significant at the $95 \%$ level according to the Student's t-test. Dark and light violet lines show correspondingly $80 \%$ and $15 \%$ SIC.

are observed over the Bering Sea in winter, where SIC is growing by $9 \%$ per decade, thus showing about $30 \%$ stronger trends compared to those reported by Cavalieri and Parkinson 2012] (6.6\% per decade). The growing SIC in the Bering Sea results in decreasing STHF with a rate of $-22 \mathrm{~W} / \mathrm{m}^{2}$ per decade. The strongest negative trends in SIT are observed in the central Arctic in cold season (FMA) and in the Barents Sea (Figure $3 \mathrm{~b})(-0.35 \mathrm{~m}$ per decade), which is consistent with Labe et al. 2018.

During the warm season (ASO) significant changes in SIC, SIT and STHF were identified primarily in the Eastern Arctic and Bering Sea (Figure 3 $\mathrm{d}-$ Figure 3). Importantly, the strongest changes are associated with the MIZ, where SIC declines over 1979-2010 with the rate of $-24 \%$ per decade and the ice is thinning with the rate of $-0.8 \mathrm{~m}$ per decade, confirming the tendencies reported by Labe et al. 2018. Associated trends in STHF are positive in the Chukchi and Beaufort Seas where they amount to $18 \mathrm{~W} / \mathrm{m}^{2}$ per decade. This is somewhat smaller compared to the values of $25 \mathrm{~W} / \mathrm{m}^{2}$ per decade for the 2003-2015 reported by Taylor et al. 2018 in the Chukchi Sea in summer. This difference in the trend estimates is likely due to the increasing rate of the Arctic amplification during the recent decades. Sea ice thinning signal comprises the whole Arctic with the mean rate of $-0.35 \mathrm{~m}$ per decade. Note that these trend patterns are consistent with those reported in the CMIP5 historical experiments [Screen et al., 2013]. The only region where SIC shows significantly positive trend in summer is the area along the north and northeast coast of Greenland where SIC shows upward 
a) MIZ, March

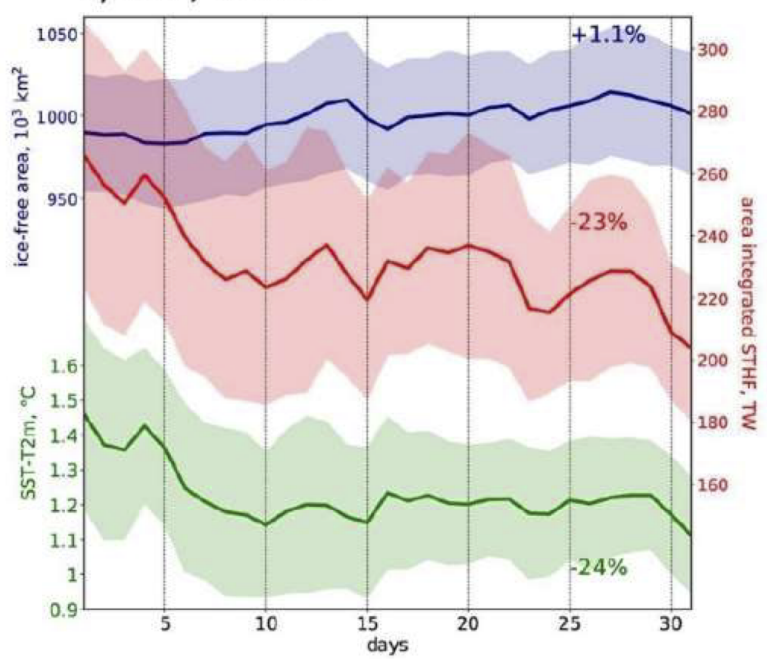

b) MIZ, September

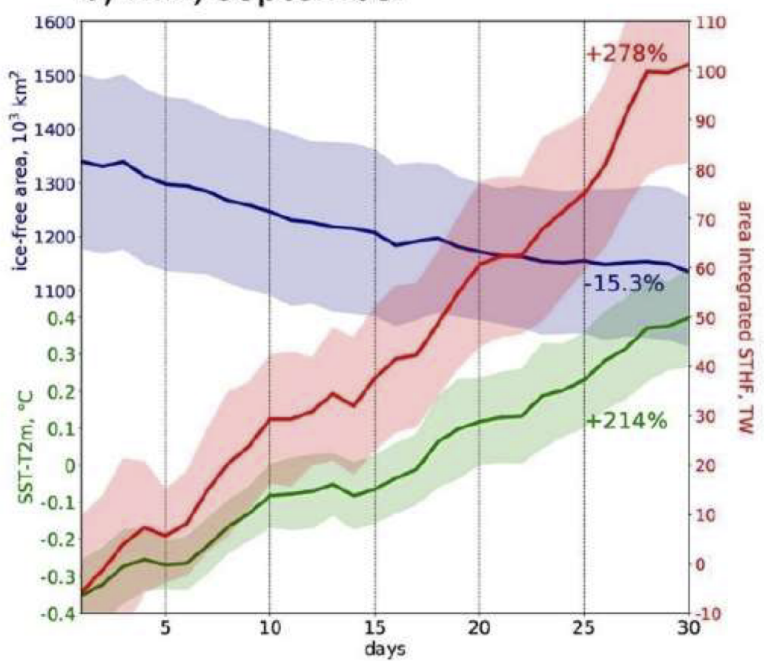

Figure 4. Mean (1979-2010 period) evolution of the ice-free area (blue) inside the MIZ (SIC 15-80\%), STHF (red) and temperature gradient (SST-T2m, green) during (a) March and (b) September. Half sigma ranges are shaded.

changes of about $10 \%$ per decade likely due to the growing sea ice export through the Fram Strait [Smedsrud, 2017]. All trends discussed above are significant at the $95 \%$ confidence level based on the Student's t-test.

Overall, the responses of trends in STHF to the tendencies in SIC and SIT in both seasons are mostly evident in the MIZ, primarily in the Eastern Barents Sea in winter and in the Eastern Arctic in summer. Also, the responses of trends in STHF to the changes in SIC are more evident compared to those to SIT. Thus, we further focus our analysis of the consistency in changes of STHF and sea ice characteristics on air-sea interaction processes over MIZ. MIZ in winter is mostly located in the Atlantic sector of the Arctic. This is relatively narrow band (9\% of the total ice-covered area, $1.4 \times 10^{6} \mathrm{~km}^{2}$ ) characterized by high values of the surface turbulent heat flux (from 30 to about $300 \mathrm{~W} / \mathrm{m}^{2}$ ). MIZ area in summer is roughly twice as small as the are of pack ice $\left(2 \times 10^{6} \mathrm{~km}^{2}\right.$ and $4.7 \times 10^{6} \mathrm{~km}^{2}$ respectively).

Figure 4 shows the composite of the transitional changes in STHF and ice-free area over MIZ during March and September (1979-2010) and explains why STHF and ice-free area are poorly correlated over MIZ. Thus, in September (Figure 4b) the composite of STHF shows an increasing by 3 times be- ing driven by surface temperature gradient. At the same time, the composite of ice-free area shows a shrinking by about $15 \%$. This demonstrates that the response of STHF to the changes in ice-free area is largely dependent on the category of SIC for which this link is evaluated.

\section{Summary and Conclusions}

In this study we analyze the importance of the marginal ice zone into the variations of the surface turbulent heat fluxes over the Arctic and interannual variability of the sea ice concentrations and sea ice thickness together with surface turbulent heat fluxes.

One the major conclusion of this study is the fact that boundary of the interacting with the ocean atmosphere and thermally isolated from the atmosphere ocean of $15 \%$ for the sea ice concentration is not optimal for studies of the air-sea interaction over the Arctic. We demonstrated that significant amount of the STHF is transferred from the ocean to the atmosphere through the areas with sea ice concentrations higher $15 \%$, the average STHF through SIC from $15 \%$ to $60 \%$ is $20-28 \mathrm{~W} / \mathrm{m}^{2}$, while through the areas with SIC $<15 \%$ it is only $10 \mathrm{~W} / \mathrm{m}^{2}$ higher, being $30-38 \mathrm{~W} / \mathrm{m}^{2}$. 
We also show a robust regional responses of STHF to SIC and SIT in MIZ over the Barents Sea (increasing STHF in response to sea ice retreat in cold season) and in the Chukchi and Beaufort Seas (increasing STHF caused by the decline in both SIC and SIT). Overall, solely sea ice extent cannot be considered as an accurate criterion for quantifying area-integrated STHF responses to sea ice variations, as the behavior of STHF over different sea ice concentration classes largely depends on the season and also on air-sea interaction processes in MIZ.

Our results provide the ground for the further analysis of the interannual to decadal variability of turbulent heat exchanges in the Arctic. More accurate analysis should take into account smaller scale air-sea interaction processes, for instance airsea exchanges over leads which despite their small areas (kilometers to tens of kilometers, [Zhang, 2018) are characterized by locally strong turbulent heat fluxes of up to $500-1000 \mathrm{~W} / \mathrm{m}^{2}[A n$ dreas et al., 1979 that can strongly affect the integrated heat fluxes over the Arctic Ocean. Similarly, strong exchanges over the polynyas may affect the area-integrated surface fluxes. Both the leads and polynyas are not accounted in the reanalysis data and climate model simulations and suggest the importance of high-resolution atmosphere-ice-ocean modeling for quantifying the associated effects.

Acknowledgments. This study was supported by the agreement \# 05.613.21.0090 with the Ministry of Science and Higher Education of the Russian Federation.

\section{References}

Andreas, E. L., T. W. Horst, A. A. Grachev, et al. (2010), Parametrizing turbulent exchange over summer sea ice and the marginal ice zone, Q.J.R. Meteorol. Soc., 136, 927-943, Crossref

Andreas, E. L., C. A. Paulson, R. M. William, et al. (1979), The turbulent heat flux from Arctic leads, Boundary-Layer Meteorology, 17, No. 1, 57-91, Crossref

Andreas, E. L., W. B. Tucker III, S.F. Ackley (1984), Atmospheric boundary-layer modification, drag coefficient, and surface heat flux in the Antarctic marginal ice zone, Journal of Geophysical Research: Oceans, 89, No. C1, 649-661, Crossref
Batrak, Y., M. Müller (2018), Atmospheric Response to Kilometer-Scale Changes in Sea Ice Concentration Within the Marginal Ice Zone, Geophysical Research Letters, 45, No. 13, 6702-6709, Crossref Birnbaum, G., C. Lüpkes (2002), A new parametrisation of surface drag in the marginal sea ice zone, Tellus, Ser. A., 54, No. 1, 107-123, Crossref

Cavalieri, D. J., C. L. Parkinson (2012), Arctic sea ice variability and trends, 1979-2010, The Cryosphere, 6, 881-889, Crossref

Cavalieri, D. J., C. L. Parkinson, et al.

(1999), Deriving long term time series of sea ice cover from satellite passive microwave multisensor data sets, $J$. Geophys. Res.: Oceans, 104, No. C7, 15,80315,814, Crossref

Cohen, J., et al. (2014), Recent Arctic amplification and extreme mid-latitude weather, Nature Geoscience, 7, No. 9, 627-637, Crossref

Deser, C., R. Tomas, et al. (2010), The seasonal atmospheric response to projected Arctic sea ice loss in the late twenty-first century, J. Climate, 23, No. 2, 333-335, Crossref

Fairall, C. W., R. Markson (1987), Mesoscale variations in surface stress, heat fluxes, and drag coefficient in the marginal ice zone during the 1983 Marginal Ice Zone Experiment, Journal of Geophysical Research: Oceans, 92, No. C7, 6921-6932, Crossref

Francis, J. A., W. Chan, et al. (2009), Winter Northern Hemisphere weather patterns remember summer Arctic sea ice extent, Geophys. Res. Lett., 36, No. 7, Crossref

Griffies, S. M., et al. (2011), The GFDL CM3 coupled climate model: characteristics of the ocean and sea ice simulations, J. Climate, 24, No. 13, 3520-3544, Crossref

Ivanov, V., M. Varentsov, et al. (2019), Arctic Sea Ice Decline in the 2010s. The Increasing Role of the Ocean - Air Heat Exchange in the Late Summer, Atmosphere, 10, No. 4, 184(1)-184(23), Crossref

Labe, Z., G. Magnusdottir, H. Stern (2018), Variability of Arctic Sea Ice Thickness Using PIOMAS and the CESM Large Ensemble, J. Climate, 31, No. 8, 3233-3247, Crossref

Maykut, C. A. (1978), Energy exchange over young sea ice in the central Arctic, J. Geophys. Res., 83, 3646-3658, Crossref

Onarheim, I. H., T. Eldevik, et al. (2018), Seasonal and regional manifestation of Arctic sea ice loss, J. Climate, 31, No. 12, 4917-4932, Crossref

Pope, J. O., T. J. Bracegirdle, et al. (2020), The impact of wintertime sea-ice anomalies on high surface heat flux events in the Iceland and Greenland Seas, Climate Dynamics, 54, No. 3-4, 1937-1952, Crossref

Saha, S., et al. (2010), The NCEP Climate Forecast System Reanalysis, Bull. Am. Meteorol. Soc., 91, 1015-1057, Crossref

Screen, J. A., I. Simmonds (2010), Increasing fall winter energy loss from the Arctic Ocean 
and its role in Arctic temperature amplification, Geophys. Res. Lett., 37, No. 16, Crossref

Screen, J. A., I. Simmonds, et al. (2013), The atmospheric response to three decades of observed Arctic sea ice loss, J. Climate, 26, No. 4, 1230-1248, Crossref

Serreze, M. C., A. P. Barrett, J. C. Stroeve, et al. (2009), The emergence of surfacebased Arctic amplification, The Cryosphere, 3, No. 1, 11-19, Crossref

Serreze, M. C., M. M. Holland, J. C. Stroeve (2007), Perspectives on the Arctic's shrinking sea-ice cover, Science, 315, No. 5818, 15331536, Crossref

Shalina, E., L. P. Bobylev (2017), Sea ice transformations in the Arctic from satellite observations, Sovremennye Problemy Distantsionnogo Zondirovaniya Zemli iz Kosmosa, 14, 28 41, Crossref

Smedsrud, L. H., M. H. Halvorsen, et al. (2017), FramStrait sea ice export variability and September Arctic sea ice extent over the last 80 years, The Cryosphere, 11, No. 1, 65-79, Crossref

Stroeve, J. C., J. Maslanik, et al. (2011), Sea ice response to an extreme negative phase of the Arctic Oscillation during winter 2009/2010, Geophys. Res. Lett., 38, No. 2, Crossref

Stroeve, J. C., T. Markus, et al. (2014), Changes in Arctic melt season and implications for sea ice loss, Geophys. Res. Lett., 41, 12161225, Crossref

Strong, C., I. G. Rigor (2013), Arctic marginal ice zone trending wider in summer and narrower in winter, Geophys. Res. Lett., 40, No. 18, 4864-4868, Crossref

Taylor, P. C., B. M. Hegyi, et al. (2018), On the Increasing Importance of Air-Sea Exchanges in a Thawing Arctic: A Review, Atmosphere, 9, No. 2, 41, Crossref

Tikhonov, V. V., M. D. Raev, et al. (2016), Satellite microwave radiometry of sea ice of polar regions: a review, Izvestiya. Atmospheric and Oceanic Physics, 52, No. 9, 1012-1030, Crossref

Vihma, T. (2014), Effects of Arctic sea ice decline on weather and climate: A review, Surveys in Geophysics, 35, No. 5, 1175-1214, Crossref

Yang, X. Y., X. Yuan, M. Ting (2016), Dynamical link between the Barents-Kara sea ice and the Arctic Oscillation, Journal of Climate, 29, No. 14, 5103-5122, Crossref

Zhang, Y., X. Cheng, et al. (2018), The potential of sea ice leads as a predictor for summer Arctic sea ice extent, The Cryosphere, 12, No. 12, 3747-3757, Crossref

Zippel, S., J. Thomson (2016), Air-sea interactions in the marginal ice zone, Elementa: Science of the Anthropocene, 4, No. 1, 000095, Crossref

Corresponding author:

Natalia Tilinina, Shirshov Institute of Oceanology RAS, 36 Nakhimovskiy Prospekt, 117997 Moscow, Russia. (tilinina@sail.msk.ru) 